\title{
1999 Conference Highlights St. Simons Island, Georgia
}

\section{View from our Rooms}

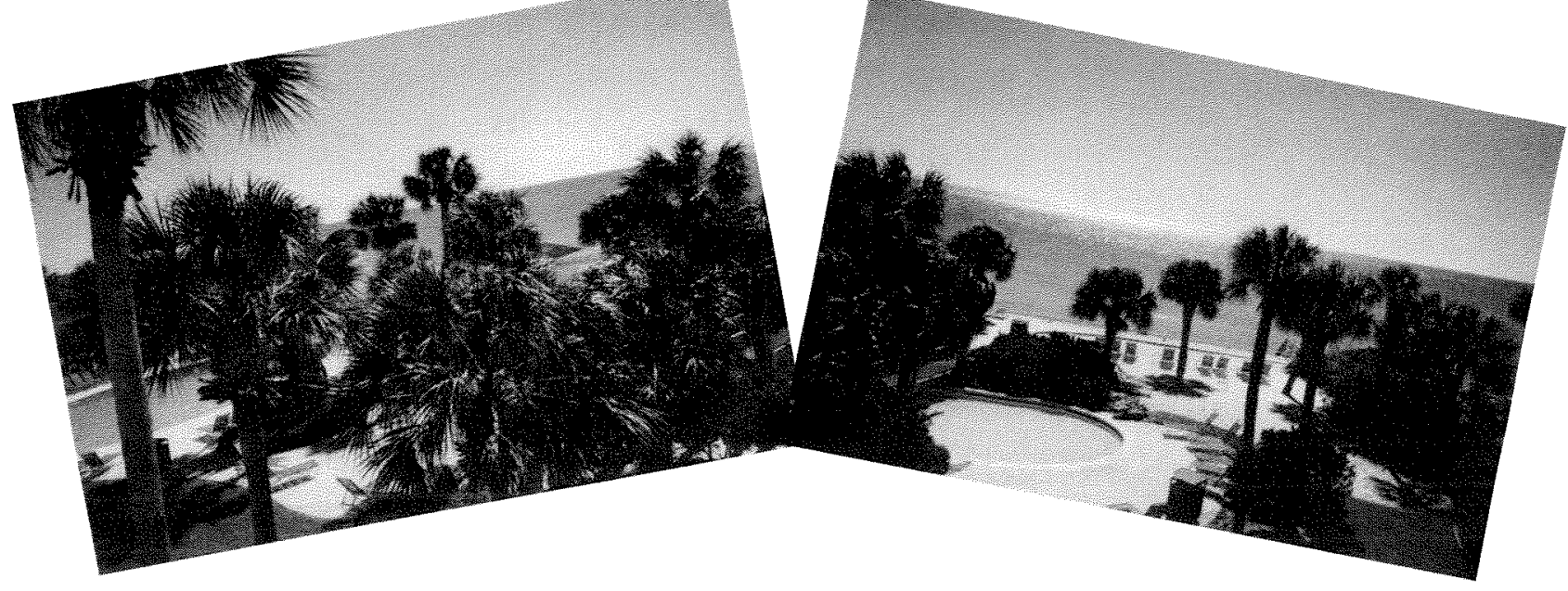

\section{Our President Hard At Work - Andy Pittman}

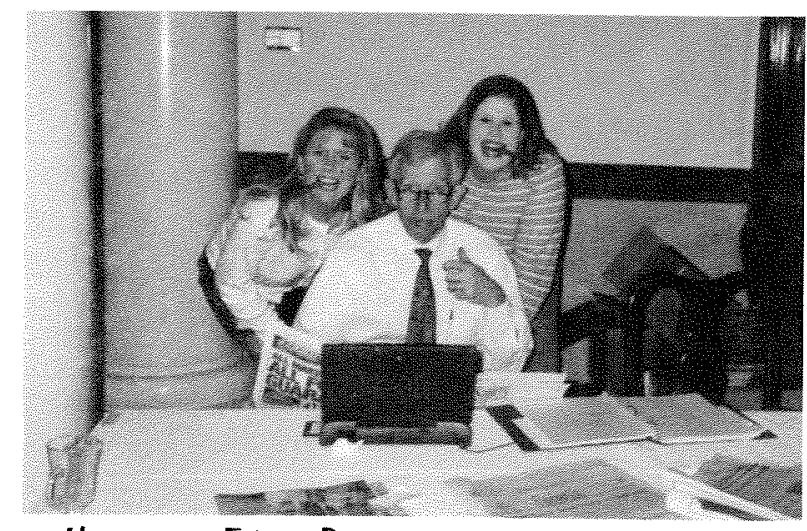

Newsletter Editor Pittman gathering information from students, Catherine and Melissa.

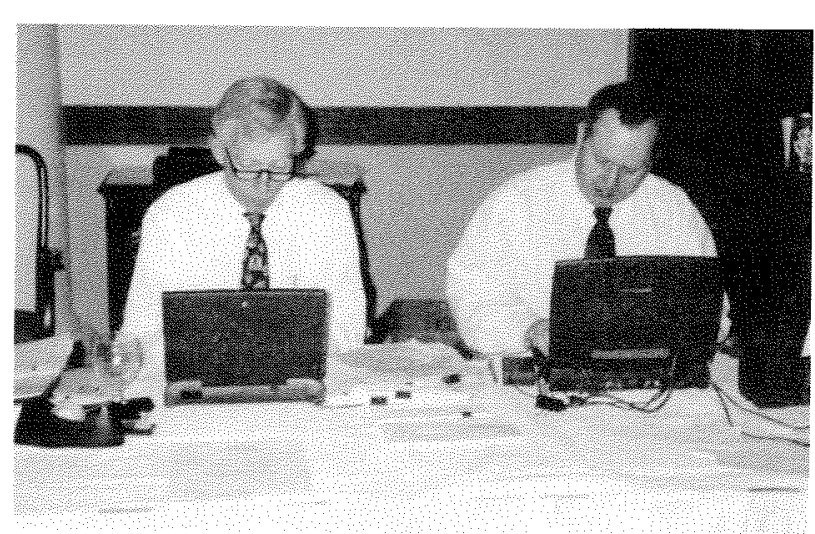

Newsletter Editor, Pittman and Assistant Journal Editor Hypes - hard at work.

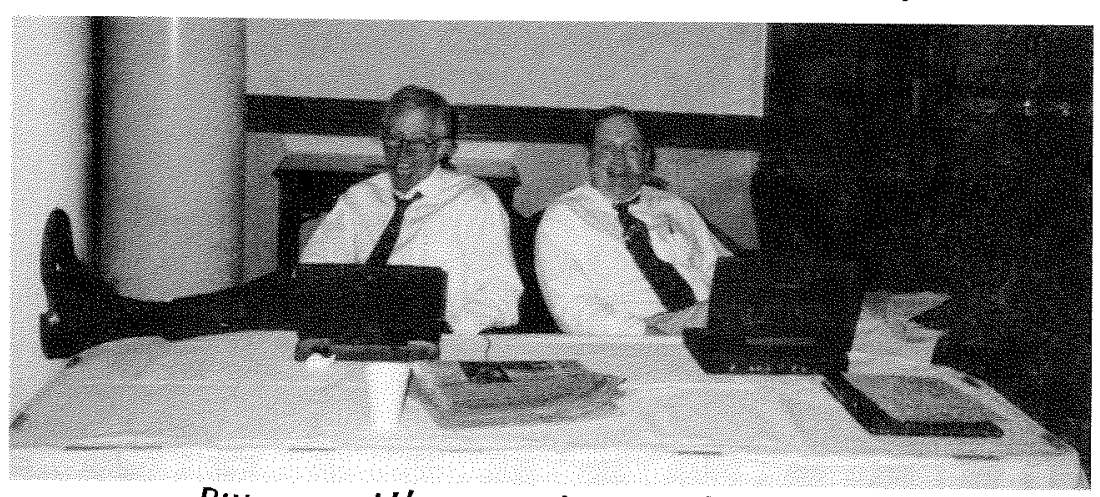

Pittman and Hypes caught at a lighter moment. 


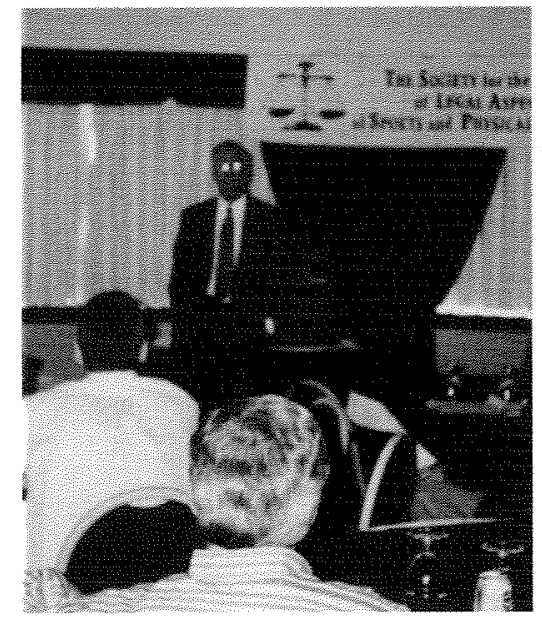

Dr. Daughtery Our

Guest Speaker Hard At Work

\section{Student Paper Award Winner Josh Grau} University of Texas at Austin

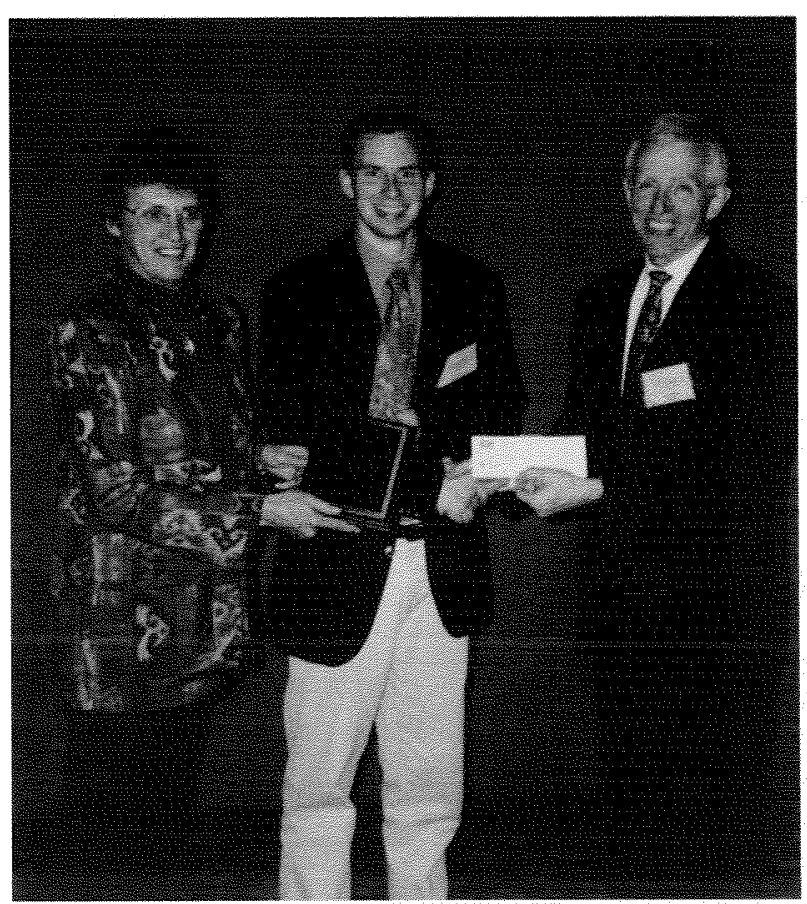

Josh receiving his award from President Pittman and Dr. Lehr, Awards Committee Chair.

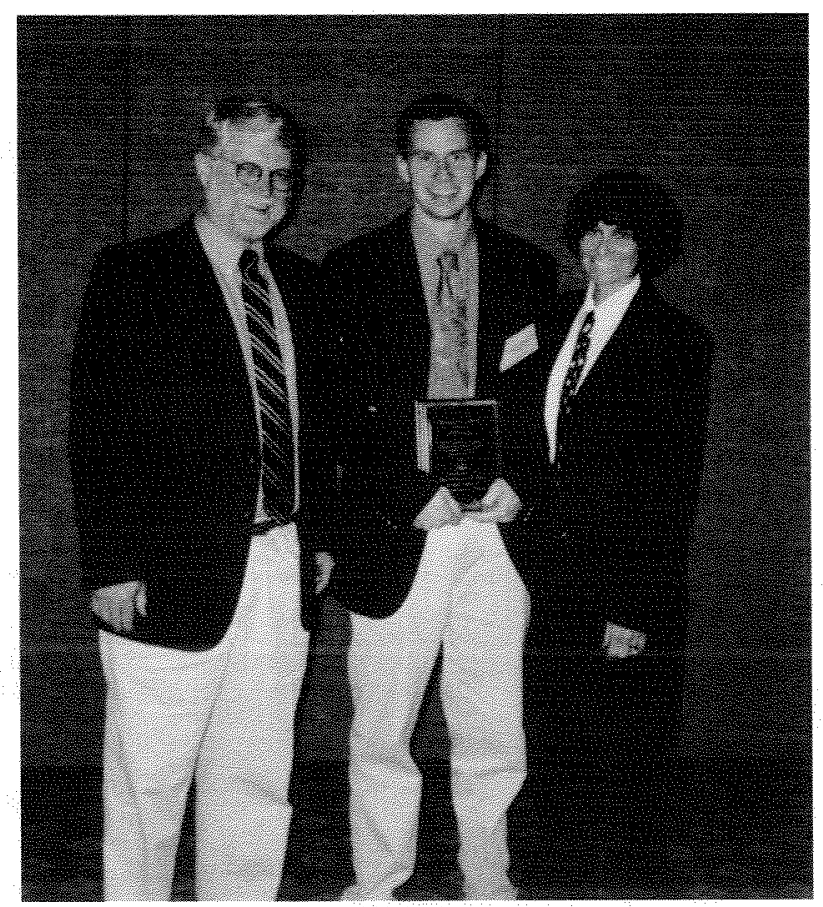

The proud Mom \& Dad. 


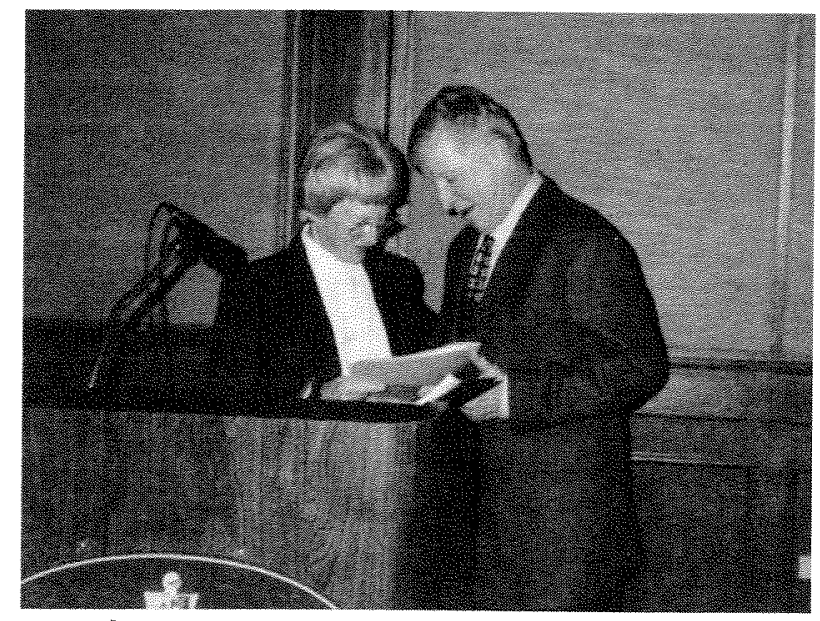

Herb receiving his award from Lynne Gaskin.

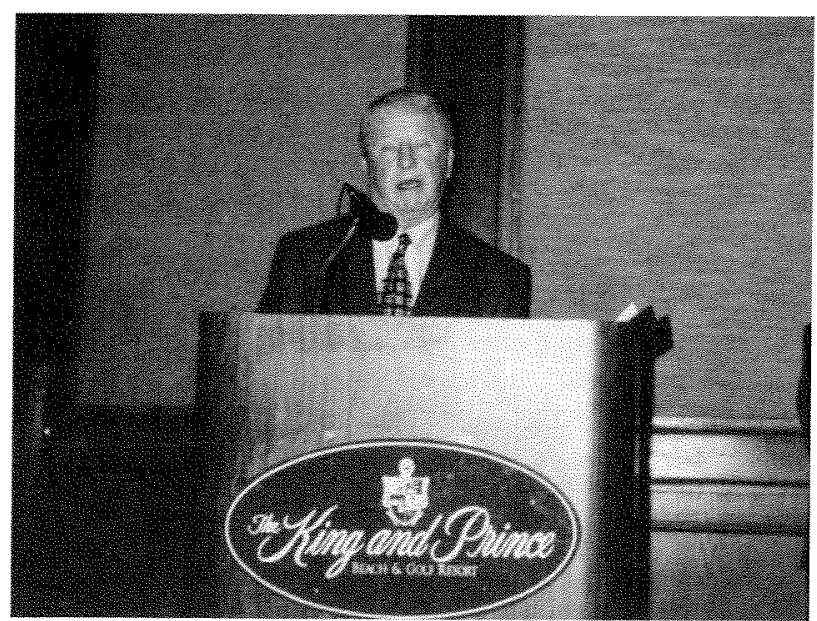

Herb accepting his award.

\section{SSLASPA Leadership Award Winner Dr. Herb Appenzeller}

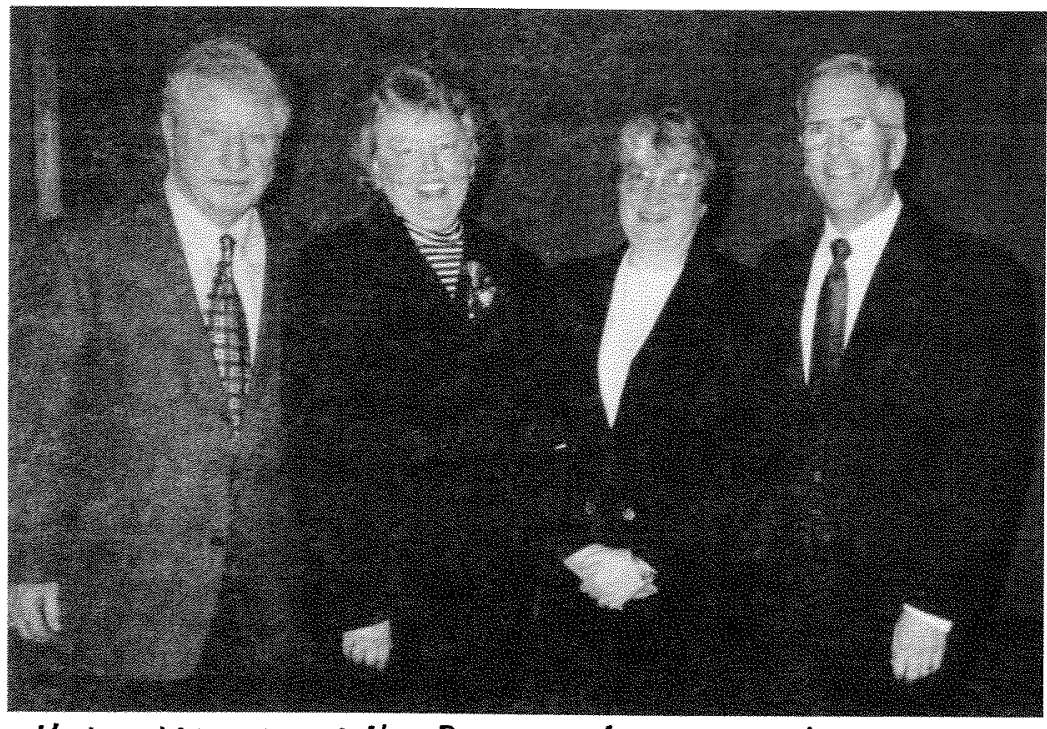

Herb and his wife with Neil Daughtery (guest speaker) and his wife.

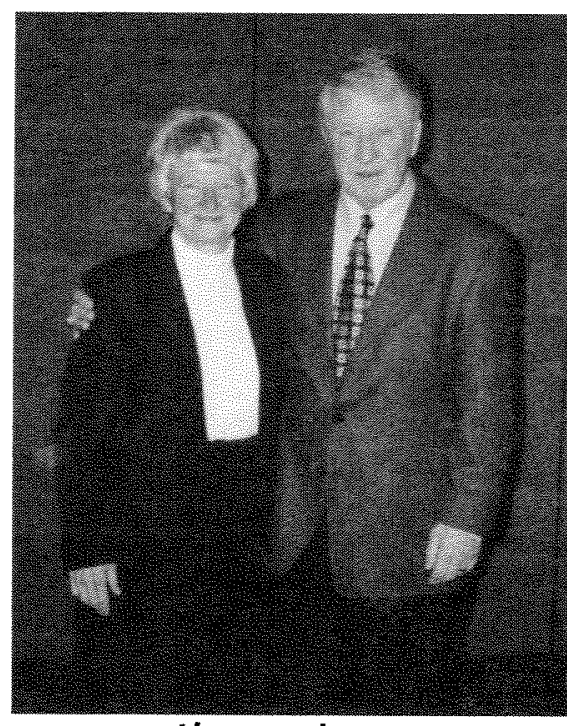

Herb and Lynhe

Herb surrounded by (I-r) Catherine Claussen (secretary), Mary Hums (past president), Andy Pittman (president), Lisa Pike Masteralexis (member-at-large), and Jon Wolohan (president-elect).

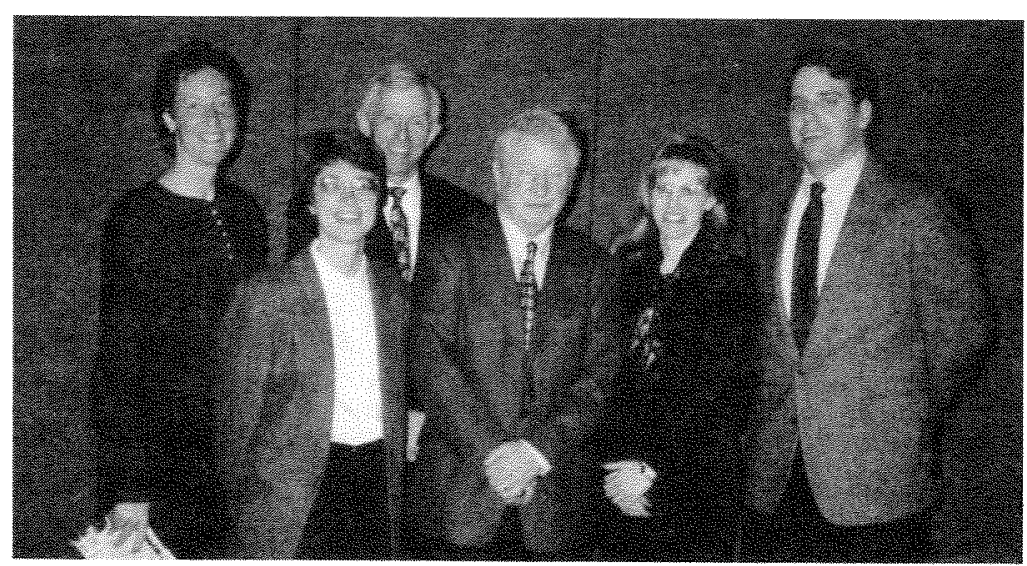

